\title{
Comparison of maternal and neonatal outcomes between acute fatty liver of pregnancy and hemolysis, elevated liver enzymes and low platelets syndrome: a retrospective cohort study
}

Sau Xiong Ang ${ }^{1}$, Chie-Pein Chen ${ }^{1}$, Fang-Ju Sun ${ }^{2}$ and Chen-Yu Chen ${ }^{1,3^{*}}$

\begin{abstract}
Background: Acute fatty liver of pregnancy (AFLP) and hemolysis, elevated liver enzymes and low platelets (HELLP) syndrome are two uncommon disorders that mimic each other clinically, but are distinct pathophysiologically. This study aimed to compare maternal and neonatal outcomes between AFLP and HELLP syndrome.

Methods: This retrospective cohort study was performed at a tertiary referral center in Taiwan between June 2004 and April 2020. We used the Swansea Criteria to diagnose AFLP, and the Tennessee Classification System to diagnose HELLP syndrome. Maternal characteristics, laboratory data, complications, and neonatal outcomes were compared. We analyzed the categorical variables with Chi-square test or Fisher's exact test and continuous variables with Student's t test or Mann-Whitney $U$ test. Subsequent logistic regression analyses adjusting by potential confounding factors with significant difference were analyzed.

Results: During the study period, 21 women had AFLP and 80 women had HELLP syndrome. There was a higher rate of preeclampsia (95.0\% versus $23.8 \%$ ) in the HELLP syndrome group compared to the AFLP group. However, the AFLP group had more other maternal complications including jaundice ( $85.7 \%$ versus $13.8 \%$ ), acute kidney injury (61.9\% versus $15.0 \%$ ), disseminated intravascular coagulopathy (66.7\% versus $8.8 \%$ ), and sepsis (47.6\% versus $10.0 \%$ ) compared to the HELLP syndrome group. Nevertheless, higher rates of small for gestational age neonates (57.1\% versus $33.3 \%$ ), neonatal respiratory distress syndrome (39.2\% versus $8.3 \%$ ) and neonatal sepsis ( $34.2 \%$ versus $12.5 \%$ ) were noted in the HELLP syndrome group.
\end{abstract}

Conclusions: AFLP is associated with a higher rate of multiple organ dysfunction in mothers, whereas HELLP syndrome is associated with a higher rate of neonatal morbidity.

Keywords: Acute fatty liver of pregnancy, HELLP syndrome, Multiple organ dysfunction, Neonatal morbidity

\footnotetext{
* Correspondence: f122481@mmh.org.tw

'Department of Obstetrics and Gynecology, Mackay Memorial Hospital, No. 92, Section 2, Zhong-Shan North Road, 10449 Taipei, Taiwan

${ }^{3}$ Department of Medicine, Mackay Medical College, New Taipei City, Taiwan

Full list of author information is available at the end of the article
}

(c) The Author(s). 2021 Open Access This article is licensed under a Creative Commons Attribution 4.0 International License, which permits use, sharing, adaptation, distribution and reproduction in any medium or format, as long as you give appropriate credit to the original author(s) and the source, provide a link to the Creative Commons licence, and indicate if changes were made. The images or other third party material in this article are included in the article's Creative Commons licence, unless indicated otherwise in a credit line to the material. If material is not included in the article's Creative Commons licence and your intended use is not permitted by statutory regulation or exceeds the permitted use, you will need to obtain permission directly from the copyright holder. To view a copy of this licence, visit http://creativecommons.org/licenses/by/4.0/. The Creative Commons Public Domain Dedication waiver (http://creativecommons.org/publicdomain/zero/1.0/) applies to the data made available in this article, unless otherwise stated in a credit line to the data. 


\section{Background}

Liver diseases during pregnancy occur in up to $3 \%$ of all pregnant women, and severe forms can cause maternal and perinatal morbidity and mortality [1]. They can be categorized into pregnancy-related and pre-existing liver disorders, of which the former includes hyperemesis gravidarum, intrahepatic cholestasis of pregnancy, preeclampsia with or without severe features, acute fatty liver of pregnancy (AFLP), and hemolysis, elevated liver enzymes and low platelets (HELLP) syndrome [1].

AFLP and HELLP syndrome, two uncommon disorders that mimic each other clinically but are distinct pathophysiologically, often arise during the third trimester and contribute to half of acute liver failure during pregnancy [2]. AFLP occurs in 1:7000-15,000 of pregnancies, compared to an incidence of $0.2-0.8 \%$ for HELLP syndrome $[3,4]$. AFLP, defined as the microvesicular fatty infiltration of hepatocytes during pregnancy, was first described by Stander and Cadden [5] in 1934. HELLP syndrome is the combination of hemolysis with microangiopathic blood smears, increased liver enzymes and low platelet counts, and was first termed by Weinstein [6] in 1982. Although still unclear, most previous studies have indicated that the main causes of AFLP are deficiency of fetal long-chain 3-hydroxyacyl coenzyme A dehydrogenase (LCHAD) and defects in fatty acid metabolism during pregnancy [7]. The cause of HELLP syndrome is thought to be due to abnormal placentation and the subsequent release of factors resulting in placental hypoperfusion, ischemia and systemic microangiopathies [8]. It might represent a severe subset of preeclampsia in the spectrum of gestational hypertensive disorders, although $15-20 \%$ of patients diagnosed as having HELLP syndrome are normotensive [9].

AFLP and HELLP syndrome should be managed promptly, yet differentiating these two disorders in timely fashion is difficult as they share similar initial clinical presentations and mainly unspecified gastrointestinal discomfort. Most previous studies were review articles that reported maternal conditions of the two disorders individually [10-12], and few studies have compared the two disorders simultaneously in a cohort study $[13,14]$. In our experience, the differential diagnosis between AFLP and HELLP syndrome has not been clearly recognized, we conducted this study to compare the maternal and neonatal outcomes between AFLP and HELLP syndrome, and further discussed the two pregnancy-related liver disorders with regards to their clinical features and laboratory findings.

\section{Methods}

This retrospective cohort study of pregnant women with liver disorders was performed at Mackay Memorial Hospital, a tertiary referral center in Taiwan, from June
2004 to April 2020. Detailed data were collected from obstetric records and neonatal databases using International Classification of Diseases (the ninth and tenth revisions) diagnosis codes. This study was approved by Mackay Memorial Hospital Institutional Review Board (IRB no. 19MMHIS291e), which advised that formal ethical approval with informed consent was unnecessary, as this study constituted a retrospective study. All personal identifiers were anonymized prior to analysis.

Patients with viral hepatitis, autoimmune hepatitis, cholestasis of pregnancy, biliary tract disease and ischemic hepatitis due to postpartum hemorrhage were excluded. We used the Swansea Criteria [3] to diagnose AFLP, and the Tennessee Classification System [15] to diagnose HELLP syndrome (Table 1). AFLP was diagnosed if the patient met six or more of the features in the absence of another explanation. Complete HELLP syndrome was diagnosed if the patient met all of the three laboratory criteria in the absence of another explanation. Patients with one or two of these laboratory criteria were defined as having partial HELLP syndrome and were also included in the study.

Maternal characteristics, laboratory data, complications, and neonatal outcomes between the two disorders were compared. Chronic hypertension during pregnancy was diagnosed if hypertension (systolic blood pressure $\geq$ $140 \mathrm{mmHg}$ and/or diastolic blood pressure $\geq 90 \mathrm{mmHg}$ ) was first detected at $<20$ gestational weeks. Gestational hypertension was diagnosed if new-onset hypertension was detected at $\geq 20$ gestational weeks without the presence of proteinuria. Preeclampsia was defined as gestational hypertension combined with proteinuria or new signs of end-organ dysfunction [16]. Preeclampsia with severe features included systolic blood pressure $\geq 160$ $\mathrm{mmHg}$ or diastolic blood pressure $\geq 110 \mathrm{mmHg}$, platelet count $<100,000 / \mu \mathrm{L}$, aspartate transaminase (AST) or alanine aminotransferase (ALT) levels twice the normal concentration, creatinine $>1.1 \mathrm{mg} / \mathrm{dL}$ or twice the normal concentration, pulmonary edema, or the new-onset of cerebral or visual disturbances [16]. Pulmonary edema was diagnosed according to clinical and radiological findings. Acute kidney injury (AKI) was defined as an increase in serum creatinine (1.5 times the normal baseline within 7 days or $\geq 0.3 \mathrm{mg} / \mathrm{dL}$ within 2 days) or oliguria (urine output $<0.5 \mathrm{~mL} / \mathrm{kg}$ per hour for $6 \mathrm{~h}$ ) [17]. Disseminated intravascular coagulopathy (DIC) was diagnosed if the women met three or more of the following criteria: thrombocytopenia $(<100,000 / \mu \mathrm{L})$, hypofibrinogenemia $(<300 \mathrm{mg} / \mathrm{dL})$, positive D-dimer level $(>40 \mu \mathrm{g} /$ $\mathrm{dL})$, and prolonged prothrombin time $(>14 \mathrm{~s})$ and activated partial thromboplastin time (>40 s) [18]. Postpartum hemorrhage was defined as a blood loss of more than $500 \mathrm{~mL}$ within $24 \mathrm{~h}$ after delivery [19]. Sepsis was diagnosed as infection with an acute increase of $\geq 2$ 
Table 1 The Swansea Criteria for diagnosis of AFLP and the Tennessee Classification System for diagnosis of HELLP syndrome

\begin{tabular}{|c|c|}
\hline Swansea Criteria & Tennessee Classification System \\
\hline Vomiting & AST > $70 \mathrm{IU} / \mathrm{L}$ \\
\hline Abdominal pain & $\mathrm{LDH}>600 \mathrm{IU} / \mathrm{L}$ \\
\hline Polydipsia or polyuria & Platelet $<100,000 / \mu \mathrm{L}$ \\
\hline \multicolumn{2}{|l|}{ Encephalopathy } \\
\hline \multicolumn{2}{|l|}{ Leukocytosis (> $\left.11 \times 10^{6} / \mathrm{mL}\right)$} \\
\hline \multicolumn{2}{|l|}{ Hypoglycemia (<72 mg/dL) } \\
\hline \multicolumn{2}{|l|}{ Hyperbilirubinemia (> 0.8 mg/dL) } \\
\hline \multicolumn{2}{|l|}{ Impaired liver function (AST or ALT > 42 IU/L) } \\
\hline \multicolumn{2}{|l|}{ Hyperuricemia (> 5.7 mg/dL) } \\
\hline \multicolumn{2}{|l|}{ Hyperammonemia (> 66 g/dL) } \\
\hline \multicolumn{2}{|c|}{ Impaired renal function (creatinine > 1.7 mg/dL) } \\
\hline \multicolumn{2}{|l|}{ Coagulopathy (PT > 14 s or aPTT > 34 s) } \\
\hline \multicolumn{2}{|l|}{ Ascites or bright liver on ultrasound scan } \\
\hline Microvesicular steatosis on liver biopsy & \\
\hline
\end{tabular}

Sequential Organ Failure Assessment points [20]. Small for gestational age (SGA) was defined as a birth weight < 10th percentile, based on the national singleton birth weight percentiles in Taiwan [21]. Intracranial hemorrhage was diagnosed by cranial ultrasound. Respiratory distress syndrome (RDS) and transient tachypnea of the newborn were differentiated by chest image, clinical presentation, and the use of surfactant therapy. Persistent pulmonary hypertension of the newborn was diagnosed by evaluating pre- and post-ductal oxygen saturation, chest image, arterial blood gas, and echocardiography [22].

Expeditious delivery was suggested once AFLP was diagnosed, whereas it was suggested if HELLP syndrome developed at $\geq 34$ gestational weeks or earlier if there was maternal distress (such as AKI, DIC, eclampsia, and suspected placental abruption), rapidly worsening laboratory values, uncontrolled hypertension, or nonreassuring fetal conditions [15]. A single course of antenatal betamethasone was administered to the women between 23 and 34 weeks of pregnancy to reduce neonatal RDS if the maternal condition allowed, followed by delivery at 24 to $48 \mathrm{~h}$ later.

SPSS version 24.0 (IBM Corporation, Armonk, NY, USA) was used for statistical analyses. The Chi-square test was used for categorical variables, and Fisher's exact test was used instead when the cell had an expected frequency less than 5 . For continuous variables, we applied the Kolmogorov-Smirnov test to determine if variables were normally distributed. The Student's t test was used for normally distributed data; otherwise, the MannWhitney $\mathrm{U}$ test was used. Logistic regression analyses adjusting by potential confounding factors with significant difference were performed and results were presented as adjusted B or adjusted odds ratio with $95 \%$ confidence interval in continuous variables and categorical variables respectively. In addition, regression analysis with an S-curve of birth weight against gestational age at delivery was plotted between the AFLP and HELLP syndrome groups. A $P$ value $<0.05$ was considered to be statistically significant.

\section{Results}

During the study period, 916 pregnant women were initially diagnosed with liver disorders, of whom 106 pregnant women met the Swansea Criteria or the Tennessee Classification System. After excluding cases with acute hepatitis B flare up $(n=1)$, ischemic hepatitis due to postpartum hemorrhage $(n=2)$, acute cholecystitis $(n=$ $1)$, and intrahepatic cholestasis of pregnancy $(n=1), 21$ women were diagnosed with AFLP and 80 with HELLP syndrome (including 18 with complete and 62 with partial HELLP syndrome) (Fig. 1).

The maternal characteristics are shown in Table 2. The maternal body mass index (BMI) at delivery in the HELLP syndrome group $(28.7 \pm 5.1 \quad[95 \%$ confidence interval $(\mathrm{CI}) 27.5,30] \mathrm{kg} / \mathrm{m}^{2}$ ) was significantly higher than that in the AFLP group $(24.4 \pm 3.3$ [95\% CI 22.7, $\left.26] \mathrm{kg} / \mathrm{m}^{2}\right)(P=0.001)$. Both maternal systolic and diastolic blood pressure levels on admission were significantly higher in the HELLP syndrome group than in the AFLP group $(P<0.001)$. The rate of twin pregnancy in the AFLP group was significantly higher than that in the HELLP syndrome group ( $28.6 \%$ versus $5.0 \%, P=0.005$ ). There were no significant differences in maternal age, gravidity, parity, and delivery age between the two 


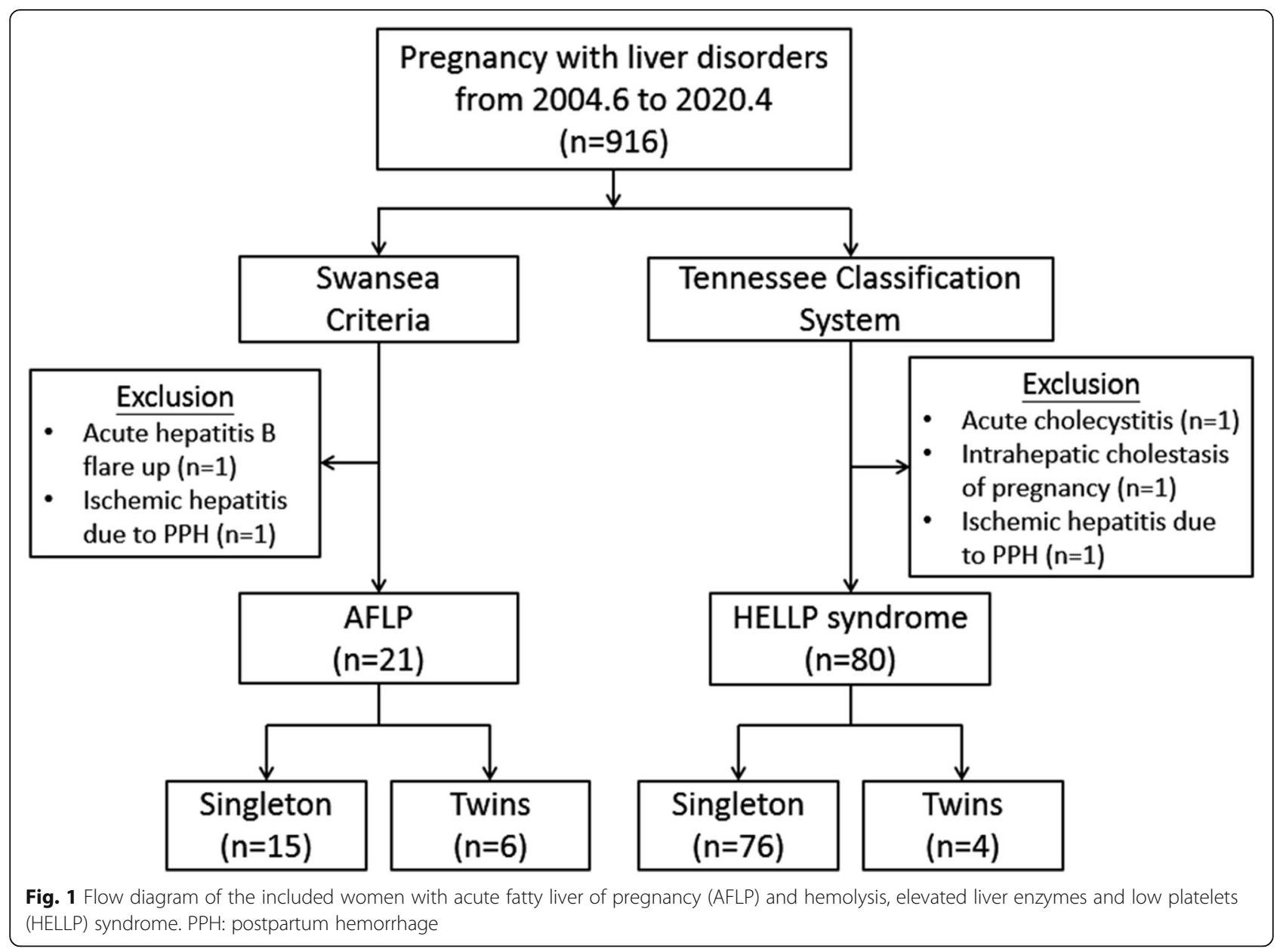

groups. The frequency of cesarean delivery was also not significantly different between the AFLP and HELLP syndrome groups $(90.5 \%$ versus $85 \%, P>0.99)$.

Table 3 shows the maternal laboratory data of the two groups. The results showed significant differences in medians or means for glucose $(85.0$ versus $98.5 \mathrm{mg} / \mathrm{dL}, P<$ 0.001 ), bilirubin ( 4.4 versus $0.9 \mathrm{mg} / \mathrm{dL}, P<0.001$ ), liver enzymes (AST: 257 versus 124 IU/L, $P=0.003$; ALT: 316 versus $135 \mathrm{IU} / \mathrm{L}, P=0.006)$, creatinine $(1.8$ versus $0.8 \mathrm{mg} / \mathrm{dL}, P<0.001$ ), and coagulation profile (prothrombin time: 14.1 versus $9.5 \mathrm{~s}, P<0.001$; activated partial thromboplastin time: 38.5 versus $27.9 \mathrm{~s}, P<0.001$; fibrinogen: 193 versus $408.1 \mathrm{mg} / \mathrm{dL}, P<0.001$ ), suggesting a higher frequency of hypoglycemia, hyperbilirubinemia, impaired liver function, impaired renal function, and coagulopathy in the AFLP group. However, the HELLP syndrome group had a significantly lower platelet count $\left(89 \times 10^{3} / \mu \mathrm{L}\right.$ versus $\left.174 \times 10^{3} / \mu \mathrm{L}, P<0.001\right)$ than the AFLP group. After adjusting by maternal BMI and twin pregnancy in a logistic regression analysis, there were no significant differences in AST, ALT, and creatinine levels between the two groups. No significant differences were noted in the levels of hemoglobin, leucocytes, uric acid, ammonia, and lactate dehydrogenase between the two groups. A further sub-analysis comparing the AFLP and complete HELLP syndrome groups revealed that there were still no significant differences in AST and ALT levels, but a higher LDH level in the complete HELLP syndrome group (765 versus $457 \mathrm{IU} / \mathrm{L}$, $P<0.001$ ) than the AFLP group (Table 3).

Table 4 shows the maternal complications of the two groups. There were significantly higher rates of preeclampsia ( $95 \%$ versus $23.8 \%, P<0.001$ ) and preeclampsia with severe features ( $95 \%$ versus $4.8 \%, P<0.001)$ in the HELLP syndrome group compared to the AFLP group. Four patients in the HELLP syndrome group had severe features of preeclampsia but were normotensive, so they were not diagnosed as having preeclampsia. However, the AFLP group had more other complications including hypoglycemia ( $28.6 \%$ versus $2.5 \%, P=0.001$ ), jaundice $(85.7 \%$ versus $13.8 \%, P<0.001)$, AKI $(61.9 \%$ versus $15 \%, P<0.001)$, DIC (66.7\% versus $8.8 \%, P<$ $0.001)$, and sepsis $(47.6 \%$ versus $10 \%, P<0.001)$ than the HELLP syndrome group. After adjusting by maternal BMI and twin pregnancy in a logistic regression analysis, we still revealed the similar significant differences. 
Table 2 Maternal characteristics of the AFLP and HELLP syndrome groups

\begin{tabular}{|c|c|c|c|}
\hline & $\begin{array}{l}\text { AFLP } \\
(n=21)\end{array}$ & $\begin{array}{l}\text { HELLP syndrome } \\
(n=80)\end{array}$ & $P$ \\
\hline Maternal age (years) ${ }^{a}$ & $\begin{array}{l}33.5 \pm 5.5 \\
(31,36)\end{array}$ & $\begin{array}{l}33.7 \pm 5.0 \\
(32.5,34.8)\end{array}$ & 0.920 \\
\hline Body mass index $\left(\mathrm{kg} / \mathrm{m}^{2}\right)$ at delivery ${ }^{a}$ & $\begin{array}{l}24.4 \pm 3.2 \\
(22.7,26)\end{array}$ & $\begin{array}{l}28.7 \pm 5.1 \\
(27.5,30)\end{array}$ & $0.001^{*}$ \\
\hline Gravida $^{b}$ & $1.5(1)$ & $2(2)$ & 0.590 \\
\hline Para $^{b}$ & $1(1)$ & $1(1)$ & 0.502 \\
\hline Nullipara ${ }^{c}$ & $15(71.4)$ & $50(62.5)$ & 0.447 \\
\hline Twin pregnancy ${ }^{c}$ & $6(28.6)$ & $4(5.0)$ & $0.005^{*}$ \\
\hline SBP on admission $(\mathrm{mmHg})^{a}$ & $\begin{array}{l}129.3 \pm 14.6 \\
(122.5,136.1)\end{array}$ & $\begin{array}{l}159.2 \pm 21.5 \\
(154.4,164)\end{array}$ & $<0.001^{*}$ \\
\hline DBP on admission $(\mathrm{mmHg})^{\mathrm{a}}$ & $\begin{array}{l}75.1 \pm 12.0 \\
(69.5,80.7)\end{array}$ & $\begin{array}{l}96.4 \pm 16.0 \\
(92.9,100)\end{array}$ & $<0.001^{*}$ \\
\hline Chronic hypertension $^{c}$ & $0(0)$ & $1(1.3)$ & $>0.99$ \\
\hline Gestational hypertension ${ }^{c}$ & $0(0)$ & $0(0)$ & $>0.99$ \\
\hline Delivery age (weeks) ${ }^{b}$ & $\begin{array}{l}34.6(3.4) \\
(33,36.3)\end{array}$ & $\begin{array}{l}33.9(6.9) \\
(32.1,34.9)\end{array}$ & 0.137 \\
\hline Cesarean delivery $^{c}$ & $19(90.5)$ & $68(85.0)$ & $>0.99$ \\
\hline
\end{tabular}

AFLP acute fatty liver of pregnancy; HELLP hemolysis, elevated liver enzymes and low platelets; SBP systolic blood pressure; DBP diastolic blood pressure

${ }^{\text {a }}$ Student's $t$ test, results are presented as mean \pm standard deviation, (95\% confidence interval)

${ }^{\mathrm{b}}$ Mann-Whitney $\mathrm{U}$ test, results are presented as median (interquartile range), (95\% confidence interval)

${ }^{C} \mathrm{Chi}$-square or Fisher's exact test, results are presented as number (percentage)

${ }^{*} P<0.05$ was considered to be statistically significant

However, the further sub-analysis revealed that there were no differences in maternal complications of hypoglycemia, AKI, and sepsis between the AFLP and complete HELLP syndrome groups. There were no significant differences in rates of pulmonary edema, postpartum hemorrhage, gastrointestinal bleeding, wound hematoma, and placental abruption between the two groups. In addition, postpartum events, length of hospital stay, intensive care unit admission rate, need for blood transfusion or liver transplantation, and maternal mortality were not statistically different between the two groups. One patient with AFLP required a liver transplantation due to a rapid deterioration in liver function. In addition, one of the women died due to HELLP syndrome complicated by posterior reversible encephalopathy syndrome and intracranial hemorrhage.

The neonatal outcomes are shown in Table 5. The birth weight of the HELLP syndrome group was significantly lower than that of the AFLP group (1686.1 \pm 735.1 [95\% CI 1518.1, 1854] versus $2235.5 \pm 591.7$ [95\% CI 1996.5, 2474.5] g, $P=0.001)$. The rate of SGA neonates was significantly higher in the HELLP syndrome group $(57.1 \%$ versus $33.3 \%, P=0.031)$. In addition, higher rates of RDS $(39.2 \%$ versus $8.3 \%, P=0.004)$ and sepsis $(34.2 \%$ versus $12.5 \%, P=0.041)$ were noted in the HELLP syndrome group. There were no significant differences in birth age, Apgar scores, sex, stillbirth, intracranial hemorrhage, transient tachypnea of the newborn, persistent pulmonary hypertension of the newborn, neonatal intensive care unit admission rate, and neonatal mortality between the two groups. Six neonates died in the HELLP syndrome group, of whom five were due to prematurity, and one was due to sepsis. A logistic regression analysis adjusting by maternal BMI and twin pregnancy still revealed the similar significant differences. A further sub-analysis comparing the AFLP and complete HELLP syndrome groups also revealed the similar results (Table 5).

An S-curve regression model was used to analyze birth weight against gestational age at delivery between the AFLP and HELLP syndrome groups, and the coefficients of determination $\left(R^{2}\right)$ were 0.836 and 0.582 , respectively (Fig. 2). It showed a gradual diverging trend of the two curves towards a higher birth weight in the AFLP group and lower birth weight in the HELLP syndrome group.

\section{Discussion}

In this study, the women with AFLP were associated with jaundice and DIC, whereas those with HELLP syndrome were associated with hypertension on admission, preeclampsia and low platelet counts. We also demonstrated a significantly higher rate of twin pregnancy in the AFLP group. However, more neonatal complications were noted in the HELLP syndrome group, such as SGA, RDS, and neonatal sepsis. Accordingly, clinical and laboratory evidence of hyperbilirubinemia, hypofibrinogenemia, and coagulopathy may help to differentiate AFLP from HELLP syndrome. 


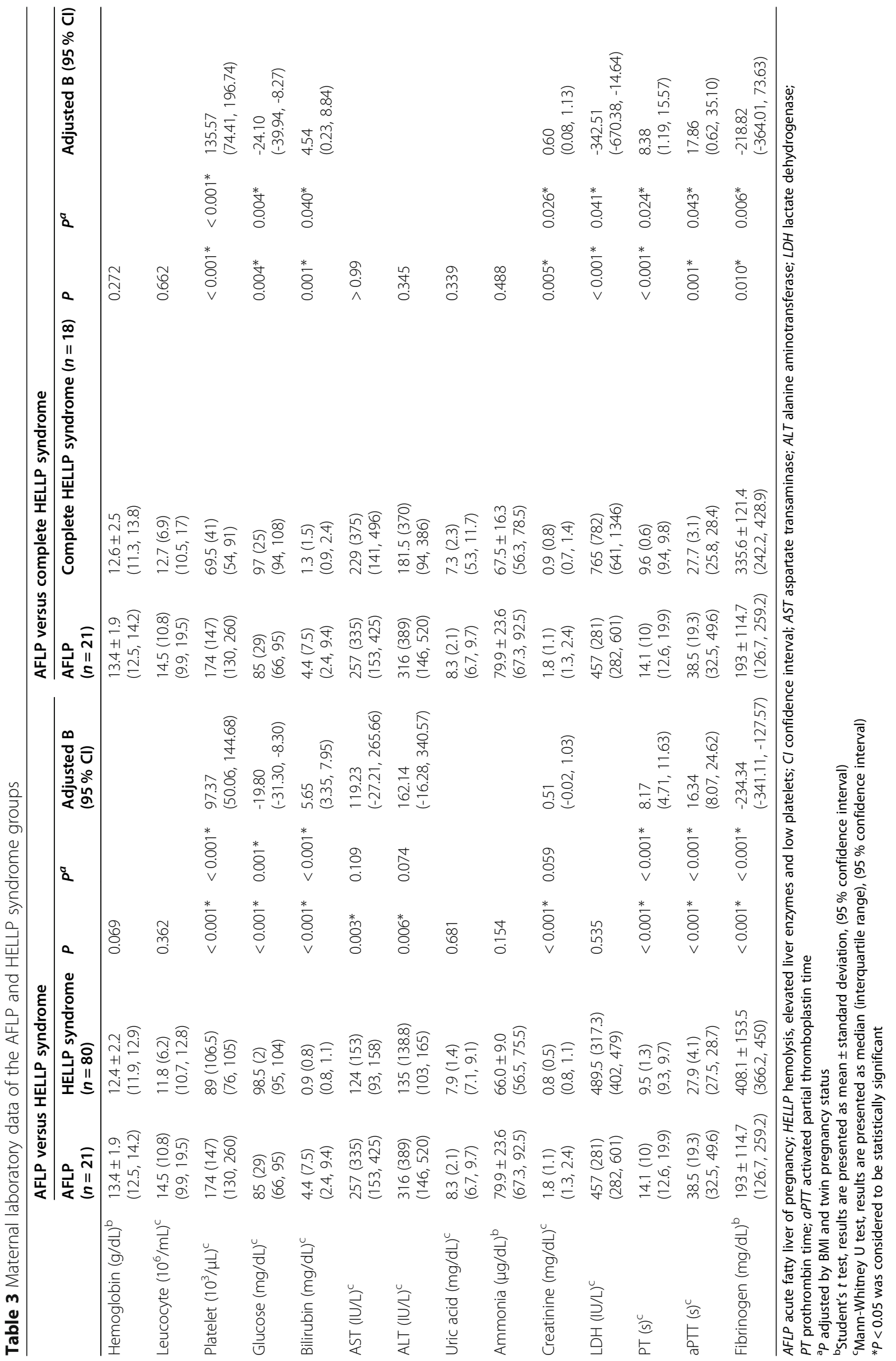




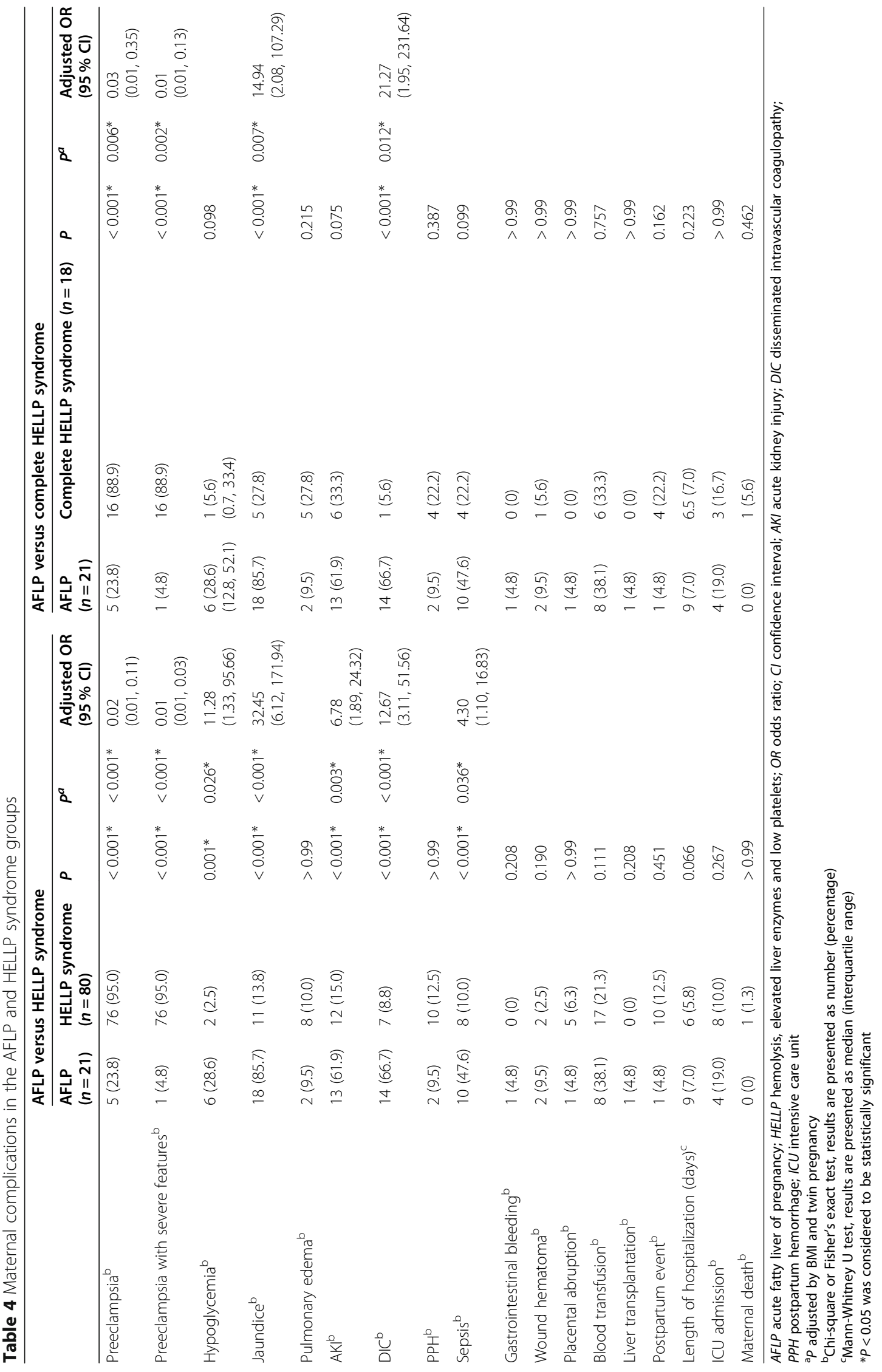




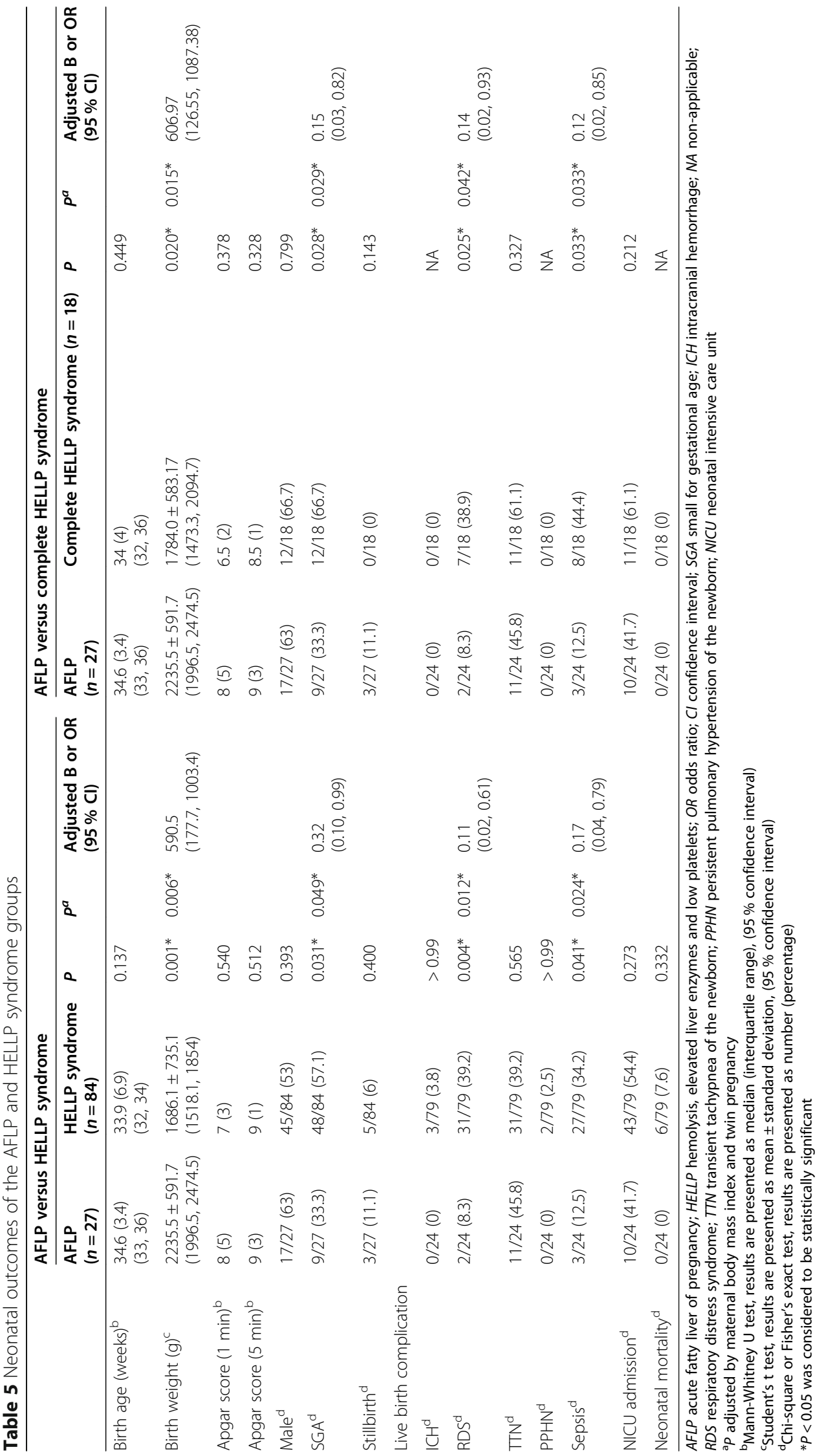




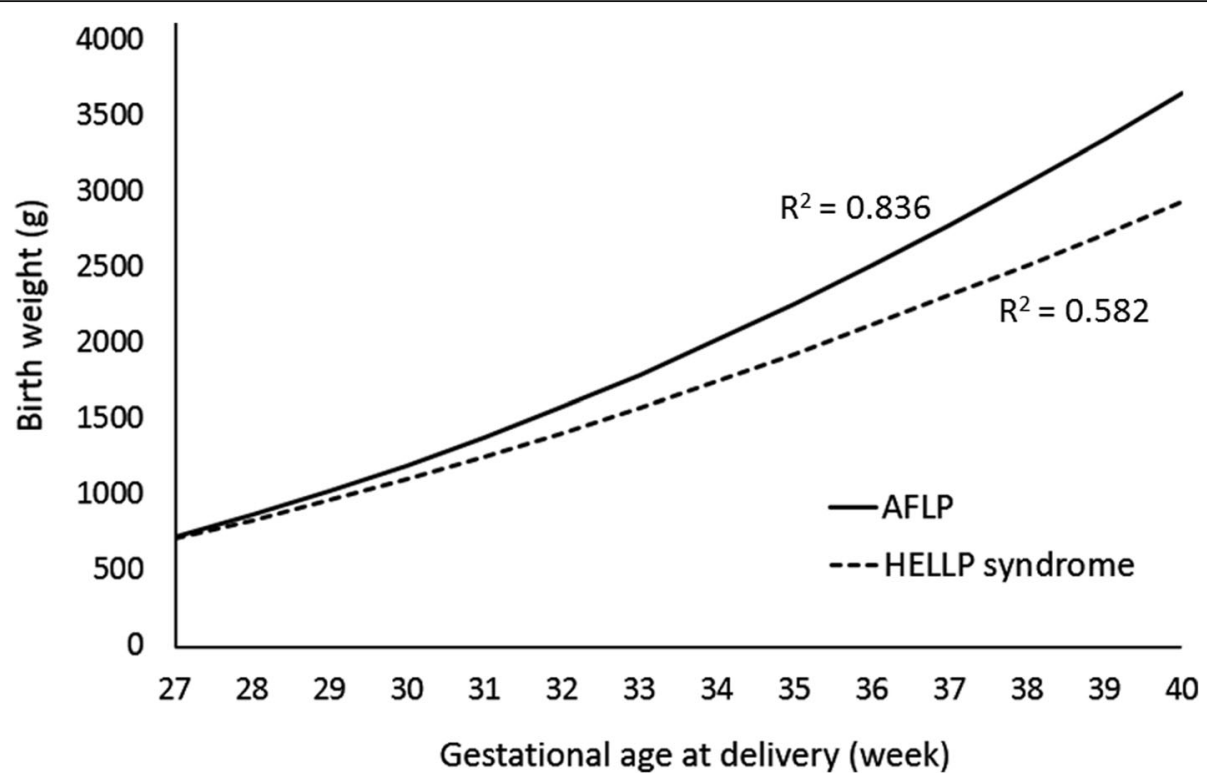

Fig. 2 S-curve regression analysis of birth weight against gestational age at delivery between the acute fatty liver of pregnancy (AFLP) and hemolysis, elevated liver enzymes and low platelets (HELLP) syndrome groups. The coefficients of determination $\left(R^{2}\right)$ for AFLP and HELLP syndrome were 0.836 and 0.582 , respectively

AFLP and HELLP syndrome differed in the magnitude of systemic involvement. Multiple organ dysfunction was more likely to occur in the patients with AFLP. Hypoglycemia results from impaired hepatic glycogenolysis, and AFLP with hepatic steatosis can inhibit bilirubin clearance resulting in hyperbilirubinemia and jaundice [23]. AKI can be caused by defective renal fatty acid oxidation, and fatty degeneration in renal tubules [24] while severe hepatic impairment can also lead to hepatorenal syndrome. The major cause of coagulopathy resulting in DIC is the reduction in hepatic production of fibrinogen and other procoagulant proteins [23]. Compared to the women with AFLP, those with HELLP syndrome had a higher BMI at delivery, which is consistent with previous studies that obesity is one of the risk factors of HELLP syndrome [25].

Even with the various maternal complications associated with AFLP, neonatal morbidities in the AFLP group were not as high as those in the HELLP syndrome group. This may be because the toxic unoxidized fatty acids due to LCHAD deficiency in the AFLP group were transferred to the mother through the placenta instead of accumulating in the fetus, thereby not increasing neonatal morbidities compared to the HELLP syndrome group.

As would be anticipated, HELLP syndrome was more likely to occur in the patients with preeclampsia and a low platelet count. Although the relationship between HELLP syndrome and preeclampsia is still controversial, HELLP syndrome is usually considered to be a severe form or a variant of preeclampsia [16]. In addition,
HELLP syndrome is related to endothelial injury and microangiopathic platelet consumption, which results in thrombocytopenia [11].

Twin pregnancy has been reported to be a risk factor for both AFLP and HELLP syndrome [13]. However, in this head-to-head comparison study, the rate of twin pregnancy in the AFLP group was significantly higher than that in the HELLP syndrome group. Most previous studies have indicated that fetal LCHAD deficiency [8] and other types of deficiencies in fetoplacental mitochondrial oxidation, such as short-chain acyl-coenzyme dehydrogenase deficiency and carnitine palmitoyltransferase deficiency are related to the development of AFLP $[26,27]$. Accordingly, it has been hypothesized that twice the amount of upstream metabolites accumulate in the circulation of mothers with twins due to these enzyme deficiencies, resulting in a lower threshold to express clinical symptoms and signs in patients with AFLP.

Another important finding of this study is the significantly higher rate of SGA neonates born to the mothers with HELLP syndrome. Although twin pregnancy is known to be a key factor leading to SGA, we found a higher rate of twin pregnancy in the AFLP group rather than the HELLP syndrome group. This could be explained by the abnormal placentation in patients with HELLP syndrome. Alterations in platelet activation, increases in pro-inflammatory cytokines, and segmental vasospasm with vascular endothelial damage could impair nutritional exchange through the feto-placental unit and subsequently result in SGA [4, 8]. In addition, higher rates of neonatal RDS and sepsis were also noted 
in the HELLP syndrome group. A correlation between SGA and RDS has been reported, possibly because intrauterine lung development can be adversely affected by fetal growth restriction due to reduced substrate supply, fetal hypoxemia and hypercortisolemia [28]. The possible mechanism of increased sepsis in SGA neonates is the delayed immune system development, which results in a higher rate of neonatal infection [29].

The strengths of this study include that this was a head-to-head comparison study of both maternal and neonatal outcomes. Moreover, the data were collected from one medical center, which could minimize management bias in different institutions. Nevertheless, there are several limitations to this study. First, the data were collected from one medical center, and thus the case numbers were limited even a near 17-year span. Second, advances in maternal and neonatal care in the recent two decades may have resulted in different maternal and neonatal outcomes. Third, in this retrospective study we did not compare the two pregnancy-related liver disorders with a reference group due to the limited laboratory data of biochemical and coagulation profile in patients without the two diseases. A further prospective casecontrol study to compare women with AFLP, HELLP syndrome, and no hepatic disease can provide more clarity on this issue.

\section{Conclusions}

Both AFLP and HELLP syndrome affect liver function yet differ in the magnitude of systemic involvement. Multiple organ dysfunction was more likely to occur in the patients with AFLP. However, more neonatal morbidities were noted in the HELLP syndrome group. These results may help us to differentiate between the two pregnancy-related liver disorders, and when explaining the management and prognosis during shared decision making with patients.

\section{Abbreviations}

IRB: Institutional Review Board; AFLP: Acute fatty liver of pregnancy; HELLP: Hemolysis, elevated liver enzymes and low platelets; LCHAD: Longchain 3-hydroxyacyl coenzyme A dehydrogenase; AST: Aspartate transaminase; ALT: Alanine aminotransferase; AKI: Acute kidney injury; DIC: Disseminated intravascular coagulopathy; SGA: Small for gestational age; RDS: Respiratory distress syndrome; BMI: Body mass index; Cl: Confidence interval

\section{Acknowledgements}

This work was supported by Ministry of Science and Technology of Taiwan (MOST-109-2314-B-195-012-MY3).

\section{Authors' contributions}

SXA participated in the study design and prepared the manuscript. CPC participated in data collection. FJS performed the quality control process and provided the statistical analysis. CYC is the principal investigator of the study and contributed to writing proposal, developing the research questions and study design, overseeing the study, and providing comments for manuscript. All authors contributed in the development, review, and approval of the final manuscript.
Funding

The authors declare that they have no funding for the research.

\section{Availability of data and materials}

Data have been collected at Mackay Memorial Hospital, a tertiary referral hospital in Taiwan. The classified and organized databases as the source of data for this study can be found at the study data registry of this hospital.

\section{Declarations}

Ethics approval and consent to participate

This study was approved by Mackay Memorial Hospital Institutional Review Board (IRB no. 19MMHIS291e), which advised that formal ethical approval with informed consent was unnecessary, as this study constituted a retrospective study. All personal identifiers were anonymized prior to analyses.

Consent for publication

Not applicable

\section{Competing interests}

The authors declare that they have no competing interests.

\section{Author details}

${ }^{1}$ Department of Obstetrics and Gynecology, Mackay Memorial Hospital, No. 92, Section 2, Zhong-Shan North Road, 10449 Taipei, Taiwan. ${ }^{2}$ Department of Medical Research, Mackay Memorial Hospital, Taipei, Taiwan. ${ }^{3}$ Department of Medicine, Mackay Medical College, New Taipei City, Taiwan.

Received: 21 October 2020 Accepted: 30 March 2021

Published online: 12 April 2021

\section{References}

1. Ch'ng CL, Morgan M, Hainsworth I, Kingham JG. Prospective study of liver dysfunction in pregnancy in Southwest Wales. Gut. 2002;51:876-80.

2. Casey LC, Fontana RJ, Aday A, et al. Acute Liver Failure (ALF) in Pregnancy: How Much Is Pregnancy-Related? Hepatology. 2020; doi:https://doi.org/10.1 002/hep.31144.

3. Liu J, Ghaziani $\Pi$, Wolf JL. Acute fatty liver disease of pregnancy: updates in pathogenesis, diagnosis, and management. Am J Gastroenterol. 2017;112: 838-46.

4. Abildgaard U, Heimdal K. Pathogenesis of the syndrome of hemolysis, elevated liver enzymes, and low platelet count (HELLP): a review. Eur J Obstet Gynecol Reprod Biol. 2013;166:117-23.

5. Stander $\mathrm{H}$, Cadden B. Acute yellow atrophy of the liver in pregnancy. Am J Obstet Gynecol. 1934;28:61-9.

6. Weinstein L. Syndrome of hemolysis, elevated liver enzymes, and low platelet count: a severe consequence of hypertension in pregnancy. Am J Obstet Gynecol. 1982;142:159-67.

7. Ibdah JA. Acute fatty liver of pregnancy: an update on pathogenesis and clinical implications. World J Gastroenterol. 2006;12:7397-404.

8. Lee NM, Brady CW. Liver disease in pregnancy. World J Gastroenterol. 2009; 15:897-906.

9. Sibai BM. The HELLP syndrome (hemolysis, elevated liver enzymes, and low platelets): Much ado about nothing? Am J Obstet Gynecol. 1990;162:311-6.

10. Than NN, Neuberger J. Liver abnormalities in pregnancy. Best Pract Res Clin Gastroenterol. 2013;27:565-75.

11. Boregowda G, Shehata HA. Gastrointestinal and liver disease in pregnancy. Best Pract Res Clin Obstet Gynaecol. 2013;27:835-53.

12. Goel A, Jamwal KD, Ramachandran A, Balasubramanian KA, Eapen CE. Pregnancy-related liver disorders. J Clin Exp Hepatol. 2014;4:151-62.

13. Minakami H, Morikawa M, Yamada T, Yamada T, Akaishi R, Nishida R. Differentiation of acute fatty liver of pregnancy from syndrome of hemolysis, elevated liver enzymes and low platelet counts. J Obstet Gynaecol Res. 2014;40:641-9.

14. Byrne JJ, Seasely A, Nelson DB, Mcintire DD, Cunningham FG. Comparing acute fatty liver of pregnancy from hemolysis, elevated liver enzymes, and low platelets syndrome. J Matern Fetal Neonatal Med. 2020 Apr;19:1-11. doi:https://doi.org/10.1080/14767058.2020.1754790. 
15. Sibai BM. Diagnosis, controversies, and management of the syndrome of hemolysis, elevated liver enzymes, and low platelet count. Obstet Gynecol. 2004;103:981-91.

16. American College of Obstetricians and Gynecologists. Gestational Hypertension and Preeclampsia: ACOG Practice Bulletin, Number 222. Obstet Gynecol. 2020;135:e237-60.

17. Mehta RL, Kellum JA, Shah SV, et al. Acute Kidney Injury Network: report of an initiative to improve outcomes in acute kidney injury. Crit Care. 2007;11: R31-1-8.

18. Audibert F, Friedman SA, Frangieh AY, Sibai BM. Clinical utility of strict diagnostic criteria for the HELLP (hemolysis, elevated liver enzymes, and low platelets) syndrome. Am J Obstet Gynecol. 1996;175:460-4.

19. Geneva. World Health Organization. WHO Recommendations for the Prevention and Treatment of Postpartum Haemorrhage. 2012.

20. Seymour CW, Liu VX, Iwashyna TJ, et al. Assessment of Clinical Criteria for Sepsis: For the Third International Consensus Definitions for Sepsis and Septic Shock (Sepsis-3). JAMA. 2016;315:762-74.

21. Hsieh WS, Wu HC, Jeng SF, et al. Nationwide singleton birth weight percentiles by gestational age in Taiwan, 1998-2002. Acta Paediatr Taiwan. 2006; $47: 25-33$

22. Bendapudi P, Rao GG, Greenough A. Diagnosis and management of persistent pulmonary hypertension of the newborn. Paediatr Respir Rev. 2015;16:157-61.

23. Nelson DB, Yost NP, Cunningham FG. Acute fatty liver of pregnancy: clinical outcomes and expected duration of recovery. Am J Obstet Gynecol. 2013; 209:456.e1-7.

24. Burghs AK, Seeing NG, Dojcinov DM, Scheuer PJ, Sherlock SV. Idiopathic acute fatty liver of pregnancy in 12 patients. Q J Med. 1982;204:481-97.

25. Lisonkova S, Razaz N, Sabr Y, et al. Maternal risk factors and adverse birth outcomes associated with HELLP syndrome: a population-based study. BJOG. 2020. doi:https://doi.org/10.1111/1471-0528.16225.

26. Matern $D$, Hart $P$, Murtha AP, et al. Acute fatty liver of pregnancy associated with short-chain acyl-coenzyme A dehydrogenase deficiency. J Pediatr. 2001;138:58-8.

27. Innes AM, Seargeant LE, Balachandra K, et al. Hepatic carnitine palmitoyltransferase I deficiency presenting as maternal illness in pregnancy. Pediatr Res. 2000:47:43-5.

28. Briana DD, Malamitsi-Puchner A. Small for gestational age birth weight: impact on lung structure and function. Paediatr Respir Rev. 2013;14:256-62.

29. Longo S, Borghesi A, Tzialla C, Stronati M. IUGR and infections. Early Hum Dev. 2014;90(Suppl 1):42-4.

\section{Publisher's Note}

Springer Nature remains neutral with regard to jurisdictional claims in published maps and institutional affiliations.

Ready to submit your research? Choose BMC and benefit from:

- fast, convenient online submission

- thorough peer review by experienced researchers in your field

- rapid publication on acceptance

- support for research data, including large and complex data types

- gold Open Access which fosters wider collaboration and increased citations

- maximum visibility for your research: over $100 \mathrm{M}$ website views per year

At $\mathrm{BMC}$, research is always in progress.

Learn more biomedcentral.com/submissions 